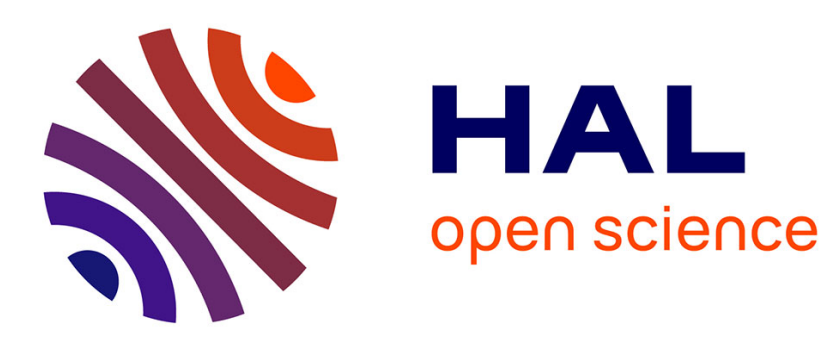

\title{
Synthesis and self-assembly of amphiphilic heterografted molecular brushes prepared by telomerization
}

\author{
Coralie Teulère, Chirine Ben-Osman, Christine Barry, Renaud Nicolaÿ
}

\section{To cite this version:}

Coralie Teulère, Chirine Ben-Osman, Christine Barry, Renaud Nicolaÿ. Synthesis and self-assembly of amphiphilic heterografted molecular brushes prepared by telomerization. European Polymer Journal, 2020, 141, pp.110080. 10.1016/j.eurpolymj.2020.110080 . hal-03003139

\section{HAL Id: hal-03003139 \\ https://hal.science/hal-03003139}

Submitted on 25 Jun 2021

HAL is a multi-disciplinary open access archive for the deposit and dissemination of scientific research documents, whether they are published or not. The documents may come from teaching and research institutions in France or abroad, or from public or private research centers.
L'archive ouverte pluridisciplinaire $\mathbf{H A L}$, est destinée au dépôt et à la diffusion de documents scientifiques de niveau recherche, publiés ou non, émanant des établissements d'enseignement et de recherche français ou étrangers, des laboratoires publics ou privés. 


\title{
Synthesis and self-assembly of amphiphilic heterografted molecular brushes prepared by telomerization
}

Coralie Teulère, Chirine Ben-Osman, Christine Barry and Renaud Nicolä**

Chimie Moléculaire, Macromoléculaire, Matériaux, ESPCI Paris, Université PSL, CNRS, 75005 Paris, France

Corresponding Author. *Email: renaud.nicolay@espci.psl.eu

\begin{abstract}
Heterografted amphiphilic molecular brushes are highly grafted macromolecules with both hydrophilic and hydrophobic side chains attached to the backbone. These macromolecules display a unique combination of properties and can self-assemble in solution to form stable structures at very low concentration. Herein, we report a straightforward and robust methodology to access such macromolecules from precursors carrying xanthate side groups. Iterative aminolysis of a fraction of the xanthates and telomerization from the resulting thiols allow preparing heterografted molecular brushes with adjustable backbone dimensions, compositions, and grafting densities, which is exemplified with polymethacrylate hydrophobic grafts and poly(methacrylic acid), poly(acrylic acid) and $\operatorname{poly}(N$-isopropylacrylamide) hydrophilic grafts. Yet, the molecular brushes display relatively high dispersities, which makes this approach not suited to synthesize well-defined heterografted molecular brushes. Nonetheless, the heterografted molecular brushes self-assemble in aqueous solution to form stable core-shell micelles, as observed by dynamic light scattering, with radii of gyration ranging from 30 to more than $100 \mathrm{~nm}$, and critical micellar concentrations as low as $0.3 \mathrm{mg} / \mathrm{mL}$.
\end{abstract}


Keywords Molecular Brushes, Heterografted, Radical Polymerization, Telomerization, Amphiphilic, Self-Assembly

\section{Introduction}

Molecular brushes are polymers constituted of a linear backbone with densely grafted shorter side chains.[1-5] This structural feature endows these macromolecular objects with unique properties, leading to novel applications in fields as different as elastomers and super-soft elastomers,[6-8] molecular probes and sensors,[9, 10] lubricants,[11] coatings,[12] photoresists[13] and imaging.[14] Among the different structures of molecular brushes accessible, brushes with side chains of different natures are of specific interest.[15, 16] In particular, heterografted brushes that combine hydrophobic and hydrophilic side chains exhibit very interesting self-assembling properties in aqueous solution.[17-24] In comparison with low molecular weight surfactants and amphiphilic block copolymers, amphiphilic brushes form more stable micelles and display lower critic micellar concentrations (CMC),[20, 21] very appealing characteristics to design drug delivery systems for example.[25, 26]

The synthesis of amphiphilic molecular brushes with hydrophobic and hydrophilic side chains randomly distributed along the backbone can be achieved via the grafting-from, $[17,20$, 24, 27] the grafting-through,[22, 28-33] and the grafting-onto methods.[34-36] A combination of these methods can also be used.[12, 19, 23, 37-39] These approaches allow preparing welldefined heterografted brushes with good control over the grafting density, as well as the composition, molar mass, and dispersity of the backbones and side chains. The grafting-from approach typically relies on living/controlled polymerization techniques, such as reversible deactivation radical polymerization (RDRP) and ring opening polymerization. It often implies successive steps of deprotection, functionalization and polymerization after the growth of the first type of side chains. The synthetic route to heterografted amphiphilic brushes may be 
simplified when grafting-through or grafting-onto methods are employed, or when they are combined with the grafting-from approach. However, the grafting-through and the graftingonto methods require the preparation of functional oligomers, which need to be quantitatively functionalized to obtain macromonomers and monofunctional oligomers, respectively. In addition, these macromonomers and functional oligomers are typically short grafts, limiting the range of architectures accessible with these two methods. The development of simple, straightforward and robust synthetic methodologies to prepare heterografted amphiphilic brushes remains a challenge to be addressed.

Grafting from and transfer to thiols were recently combined to prepare molecular brushes with poly(meth)acrylate and polyamide side chains, by telomerization from backbones carrying thiol side groups.[40] This very simple methodology allows preparing brushes with good control over the backbone size and grafting density, but with high dispersities of the grafts. Herein, we assess the possibility of extending this methodology to the synthesis of amphiphilic heterografted molecular brushes, through successive telomerizations of the side chains. A series of brushes with polymethacrylate hydrophobic side chains and poly((meth)acrylic acid) or polyacrylamide hydrophilic side chains could be prepared. The grafting densities of the brushes was kept constant, while the impact of the composition and side chain length on the selfassembly of the amphiphilic brushes in aqueous solution was investigated. Starting from a single polyxanthate precursor, molecular brushes with molar masses ranging between $480 \mathrm{~kg} / \mathrm{mol}$ and $935 \mathrm{~kg} / \mathrm{mol}$, and with average degrees of polymerization (DPs) of the side chains comprised between 45 and 185 were prepared. These objects self-assembled in water to produce stable core-shell micelles, with CMCs as low as $0.3 \mathrm{mg} / \mathrm{L}$. 


\section{Experimental section}

\subsection{Materials}

Unless otherwise noted, reagents and solvents were commercially available and used without further purification. Butyl methacrylate (BMA, 99\%), methyl methacrylate (MMA, 99\%), benzyl methacrylate (BenzMA, 98\%), tert-butyl acrylate ( $t$ BA, 99\%) and tert-butyl methacrylate ( $t$ BMA, 99\%) were purified by passing through a column filled with basic alumina to remove inhibitors or antioxidants. Azobisisobutyronitrile (AIBN) was recrystallized from methanol and $N$-isopropylacrylamide (NIPAM) was recrystallized twice from hexanes.

\subsection{Methods}

Nuclear magnetic resonance (NMR) spectroscopy. ${ }^{1} \mathrm{H}$ spectra were recorded at $297 \mathrm{~K}$ on a Bruker AVANCE 400 spectrometer at $400 \mathrm{MHz}$, and referenced to the residual solvent peak $\left({ }^{1} \mathrm{H}, \delta 7.26\right.$ for $\left.\mathrm{CDCl}_{3}\right)$. Monomer conversions were determined by ${ }^{1} \mathrm{H}$ NMR.

Size exclusion chromatography (SEC). SEC analyses were performed on a Viscotek GPCmax/VE2001 connected to a quadruple detection array (Viscotek TDA 305; refractometer, viscosimeter, static light scattering and UV detection at $250 \mathrm{~nm}$ ) using three thermostated columns (LT5000L) in THF as eluent at $35^{\circ} \mathrm{C}$ and at a flow rate of $1 \mathrm{~mL} \cdot \mathrm{min}^{-1}$. Molar masses $\left(M_{\mathrm{n}}\right.$ and $\left.M_{\mathrm{w}}\right)$ and dispersities $(\nexists)$ of isolated brushes were obtained by triple detection. The apparent molar masses and dispersities of non-isolated polymers were determined with a calibration based on linear poly(methyl methacrylate) (PMMA) standards.

Fourier-transform infrared (FTIR) spectroscopy. FTIR spectroscopy was conducted on a Tensor 37 spectrometer from Bruker. Polymers, before and after tert-butyl ester hydrolysis, were dissolved in dioxane, spread on a diamond and analyzed at $120^{\circ} \mathrm{C}$ to remove the dioxane and obtain a film of polymer.

CMC determination. CMC measurements were performed using a fluorescence spectrometer Jasco FP-8200. Pyrene was used as a fluorescence probe to determine the CMC 
value of amphiphilic brush copolymers. In a typical experiment, a solution of pyrene $\left(1.2 \times 10^{-}\right.$

$\left.{ }^{4} \mathrm{M}\right)$ in acetone was prepared in advance. Micellar solutions of polymer brushes $\left(1 \mathrm{~g} . \mathrm{L}^{-1}\right)$ were diluted to a series of concentrations ranging from $1 \times 10^{-5}$ to $1 \times 10^{-2}$ g. $\mathrm{L}^{-1}$ with deionized water. $100 \mu \mathrm{L}$ of the pyrene solution was added to different vials and the acetone was allowed to evaporate at room temperature under a fume hood. Then, polymer solutions at various concentrations were added to the different vials to reach a pyrene concentration of $6 \times 10^{-7} \mathrm{M}$. The pyrene/copolymer solutions were equilibrated at room temperature in the dark for $24 \mathrm{~h}$ before measurements. Analyses were performed from 310 to $350 \mathrm{~nm}$ using an excitation wavelength of $373 \mathrm{~nm}$.

Dynamic light scattering (DLS). DLS measurements were performed on a ALV/CGS2303 Compact Goniometer System with a He-Ne laser $(\lambda=632.8 \mathrm{~nm}) .3 \mathrm{~mL}$ of diluted solutions were introduced in glass cuvettes and analyzed from $30^{\circ}$ to $150^{\circ}$.

Transmission electron microscopy (TEM). TEM observations were performed with a CEM 902 Zeiss microscope operated under a voltage acceleration of $80 \mathrm{kV}$. The samples were prepared by placing a drop of micellar solution on copper grids coated with thin film of carbon. After complete evaporation of water, the sample was stained with ruthenium tetroxide.

\subsection{Synthesis}

The synthesis of xanthate ethyl methacrylate (XEMA), 4-(2-acryloxyethoxy)benzaldehyde (4-AEBA) and polyxanthate brush precursors were carried out according to literature procedures.[40,41]

General procedure for the synthesis of heterografted brushes by telomerization. The heterografted brushes were synthesized via a two-step process.

Step 1. In a typical experiment, the polyxanthate precursor and toluene (same volume as the volume of monomer used in the subsequent telomerization) were charged in a Schlenk flask placed under nitrogen atmosphere. Butylamine (0.6 eq. with respect to xanthate functions) was 
added and the reaction mixture was stirred at room temperature for $24 \mathrm{~h}$. Deoxygenated MMA (60 eq. with respect to thiol groups) and a $100 \mu \mathrm{L}$ solution of $\mathrm{AIBN}$ ( 0.01 eq. with respect to thiol groups) in anisole were added to the reaction mixture. Then, the flask was placed in an oil bath thermostated at $65{ }^{\circ} \mathrm{C}$ for $24 \mathrm{~h}$. Samples were withdrawn periodically under $\mathrm{N}_{2}$ atmosphere for monomer conversion and molar mass determination. The reaction was stopped by placing the flask in an ice-water bath, and the polymer was isolated by successive precipitations into methanol.

Step 2: one-pot process. In a typical experiment, a brush polymer obtained according to step 1 and toluene ( 1 to 2.5 times the volume of monomer used in the subsequent telomerization) were charged in a Schlenk flask placed under nitrogen atmosphere. Butylamine (2.5 eq. with respect to the remaining xanthate functions) was added and the reaction mixture was stirred at room temperature for $24 \mathrm{~h}$. Deoxygenated $t$ BMA (60 eq. with respect to thiol groups) and a $100 \mu \mathrm{L}$ solution of AIBN (0.01 eq. with respect to thiol groups) in anisole were added to the reaction mixture, and the flask was then placed in an oil bath thermostated at $65^{\circ} \mathrm{C}$ for 24 hours. Samples were withdrawn periodically under $\mathrm{N}_{2}$ atmosphere for monomer conversion and molar mass determination. The reaction was stopped by placing the flask in an ice-water bath, and the polymer was isolated by successive precipitations into methanol.

Step 2: two-pot process. In a typical experiment, a brush polymer obtained according to step 1 and DMF (30 wt\% solution) were charged in a Schlenk flask placed under nitrogen atmosphere. Butylamine (2.5 eq. with respect to the remaining xanthate functions) was added and the reaction mixture was stirred at room temperature for $24 \mathrm{~h}$. The polymer was isolated by successive precipitations into dry diethyl ether and dried under vacuum. The resulting polymer was then dissolved in toluene (volume identical to the volume of tert-butyl acrylate; DMF was used instead of toluene for the telomerization of NIPAM), deoxygenated tert-butyl acrylate (115 eq. with respect to thiol groups) and a $100 \mu \mathrm{L}$ solution of $\operatorname{AIBN}(0.01$ eq. with respect to 
thiol groups) in anisole were added. The flask was then placed in an oil bath thermostated at $65{ }^{\circ} \mathrm{C}$ for 3.5 hours. The reaction was stopped by placing the flask in an ice-water bath, and the polymer was isolated by successive precipitations into methanol.

General procedure for the hydrolysis of the tert-butyl ester functions of PtBMa and PtBA. This procedure is adapted from literature.[42] The heterografted brush copolymer containing $\mathrm{P} t \mathrm{BMA}$ or $\mathrm{P} t \mathrm{BA}$ grafts is dissolved in dioxane (10 $\mathrm{wt} \%$ in solution) and concentrated $\mathrm{HCl}$ is added. The mixture is refluxed for $4.5 \mathrm{~h}$ and the polymer is precipitated into diethyl ether and dried under vacuum at $50^{\circ} \mathrm{C}$.

Preparation of micellar solutions. The amphiphilic brush is dissolved in DMF at a concentration of $1 \mathrm{wt} \%$. Deionized water is added under vigorous stirring with a flow rate of $0.7 \mathrm{~mL} / \mathrm{min}$ until reaching a concentration of $1 \mathrm{~g} / \mathrm{L}$. Then, the dispersion is stirred for $2 \mathrm{~h}$ at room temperature. DMF is then removed by dialysis (MW cutoff, $7.0 \mathrm{kDa}$ ) against deionized water for $24 \mathrm{~h}$. Deionized water is regularly replaced with fresh deionized water. The obtained dispersion displays a bluish tinge characteristic of colloidal aggregates. No macroscopic phase separation is observed upon standing at room temperature for several weeks, suggesting the formation of stable aggregates.

Thiol titration of heterografted polymer brushes. This protocol is adapted from literature.[40] Thiol titration after the first step of the heterografted brush synthesis: $0.5 \mathrm{~g}$ of the isolated brush carrying hydrophobic side chains is used for thiol titration. Since the remaining xanthate functions have strong UV absorbance, the first step consists in the deprotection of the remaining xanthate moieties. To this aim, the polymer is dissolved in THF and 2.5 equivalents of butylamine with respect to the xanthate functions are added. The mixture is stirred for $24 \mathrm{~h}$ at room temperature and the polymer is recovered by successive precipitations into dry diethyl ether. The polymer is dissolved in THF. Then, 5 equivalents of 4-AEBA with respect to the initial concentration of xanthate side groups, two drops of tributylphosphine and one drop of 
water are added. The mixture is stirred at room temperature for 3 days. The polymer is then recovered by successive precipitations into methanol, dried under vacuum and dissolved in THF for UV analysis.

Thiol titration after the second step of the heterografted brush synthesis: $0.5 \mathrm{~g}$ of the isolated polymer is used for thiol titration. The polymer is dissolved in THF and 5 equivalents of 4AEBA with respect to the initial concentration of xanthate side groups, two drops of tributylphosphine and one drop of water are added. The mixture is stirred at room temperature for 3 days. The polymer is then recovered by successive precipitations into methanol, dried under vacuum and dissolved in THF for UV analysis.

\section{Results and Discussion}

\subsection{Synthesis, characterization and self-assembly of a poly(PMMA-stat-PMAA)} heterografted brush

\subsubsection{Synthesis and characterization of a poly(PMMA-stat-PMAA) heterografted brush}

It has been reported recently that polymers with pendant thiols can be used to access molecular brushes with poly(meth)acrylate and polyamide side chains.[40] With this methodology, the side chains grow sequentially via telomerization over very short periods of time, in sharp contrast to molecular brushes prepared using RDRP techniques, for which the side chains grow continuously and uniformly during the entire course of the polymerization (Scheme S1). As a consequence, the synthesis of molecular brushes by telomerization provides poor control over side chains dispersity. 

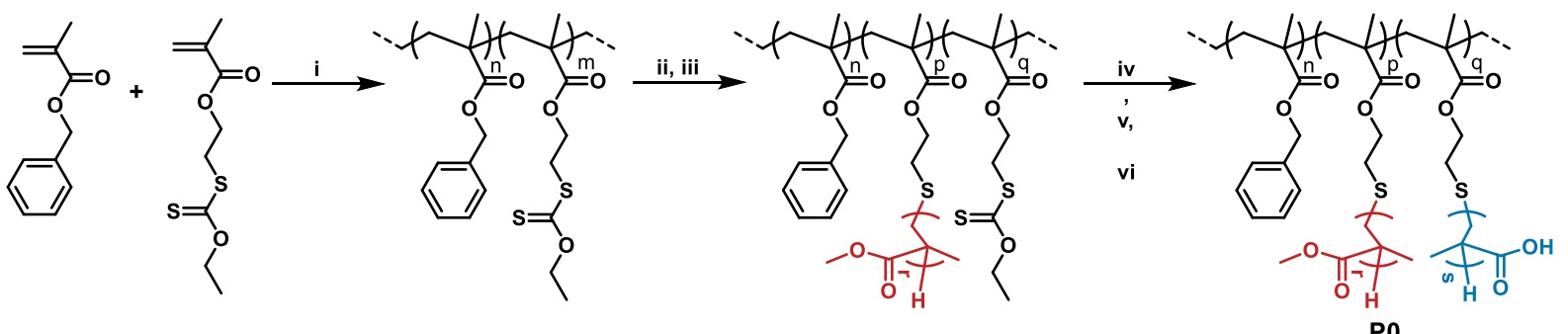

PO

Scheme 1. Synthesis of a poly(MMA-stat-MAA) heterografted polymer brush, P0: (i) AIBN, cumyl dithiobenzoate; (ii) butylamine; (iii) MMA, AIBN; iv) butylamine; (v) $t \mathrm{BMA}$, AIBN; (vi) hydrochloric acid.

Alkyl xanthates are efficient thiol protecting groups. They can be used to prepare polymers with thiol side groups through radical (co)polymerization of (meth)acrylate monomers carrying a xanthate moiety and subsequent aminolysis of the xanthate functions with primary alkyl amines.[41, 43] Interestingly, the quantitative aminolysis of xanthates can be performed at room temperature in various solvents, without the need to use a large excess of primary amines. [44, 45] Furthermore, the $O$-thiocarbamate by-product released during the xanthate aminolysis does not interfere with the telomerization of methacrylates, allowing to conduct thiol deprotection and subsequent telomerization from the resulting polythiol in a single-pot.[40] These attributes could offer the possibility to prepare heterografted molecular brushes with side chains randomly distributed along the brush backbones via iterative sequences of xanthate deprotection and telomerization (Scheme 1).

To test this possibility, a protected polythiol with a $M_{\mathrm{n}}$ of $25 \mathrm{~kg} / \mathrm{mol}$ (DP of $c a$. 130) and $30 \mathrm{~mol} \%$ of XEMA repeating units was prepared by reversible addition-fragmentation chain transfer (RAFT) copolymerization of XEMA and BenzMA. The growth of the brush side chains was then performed in two steps. In the first step, approximately half of the xanthates were turned into thiols by aminolysis with butylamine (Scheme 1). The deprotection was monitored by ${ }^{1} \mathrm{H}$ NMR, using the benzylic protons of BenzMA as a standard (Figure S1). NMR analysis indicated that $46 \%$ of the pendant xanthates were aminolyzed into thiols. Without polymer 
isolation, PMMA side chains were grown via transfer to the pendant thiols. To do so, 60 equivalents of MMA and $1 \mathrm{~mol} \%$ of AIBN with respect to the thiol moieties were added and the mixture was heated at $65^{\circ} \mathrm{C}$ for $24 \mathrm{~h}$. The final MMA conversion was $68 \%$ according to ${ }^{1} \mathrm{H}$ NMR analysis. The SEC traces of the brush copolymer shifted toward lower elution volume (higher molecular weight) with monomer conversion and the signal associated to the backbone decreased rapidly with monomer conversion (Figure 1). In the second step, the remaining xanthate protecting groups were removed quantitatively by aminolysis, using 2.5 eq. of butylamine with respect to the xanthates, and $\mathrm{P} t \mathrm{BMA}$ side chains were grown by telomerization using a ratio $[\text { Monomer }]_{0} /[\mathrm{SH}]_{0} /[\mathrm{AIBN}]_{0}$ similar to the step 1 , i.e. $[t \mathrm{BMA}]_{0} /[\mathrm{SH}]_{0} /[\mathrm{AIBN}]_{0}=$ $60 / 1 / 0.01$. The final conversion of $t$ BMA was lower ( $c a .30 \%)$ than that of MMA at the end of the first step. This result is consistent with the lower concentration of $t$ BMA ( $30 \mathrm{vol} \%$ ) used in the second telomerization, as compared to a concentration of MMA (50 vol\%) used in the first step. Indeed, a larger volume of toluene had to be employed to completely dissolve the brush carrying PMMA side chains. The SEC traces of the molecular brush shifted toward lower elution volume with the progress of the polymerization, indicating that side chains grew continuously from the backbone in the second step (Figure 1). The brush copolymer poly(PMMA-stat-PtBMA) was isolated by precipitation into methanol and subsequently analyzed by SEC triple detection in THF, to determine its absolute number average molar mass $\left(M_{\mathrm{n}}=151 \mathrm{~kg} / \mathrm{mol}\right)$ and dispersity $(\nexists=1.8)$. The isolated brush copolymer was also characterized by ${ }^{1} \mathrm{H}$ NMR (Figure S2), which confirmed the presence of both PMMA and P $t$ BMA side chains. Based on the final MMA and $t$ BMA conversions measured at the end of each telomerizations, the ratio BenzMA/MMA/tBMA in the final poly(PMMA-stat-P $t$ BMA) brush should be $1 / 8.16 / 4.1$. The ${ }^{1} \mathrm{H}$ NMR characterization of the isolated heterografted brush copolymer gave a ratio BenzMA/MMA/tBMA of $1 / 9.07 / 2.66$. Therefore, the ratio BenzMA/MMA measured by ${ }^{1} \mathrm{H}$ NMR (1/9.07) matched well the theoretical ratio calculated 
from monomer conversion (1/8.16), while the SEC traces did no show the presence of free oligomers during the growth of the PMMA side chains (Figure 1). The slightly higher BenzMA/MMA ratio in the isolated brush $(+11 \%)$, as compared to the theoretical one, likely results from a combination of inaccuracies in weighing and margin of errors of NMR measurements. In sharp contrast, the ratio BenzMA/tBMA measured by ${ }^{1} \mathrm{H}$ NMR analysis of the isolated poly(PMMA-stat-PtBMA) brush was significantly lower $(-35.3 \%)$ than the theoretical ratio calculated from monomer conversion. This discrepancy indicates that free oligomers were formed during the growth of the PtBMA side chains. This hypothesis is consistent with the tail towards low molar masses observed on the SEC traces of the molecular brushes during the growth of the $\mathrm{P} t \mathrm{BMA}$ side chains (Figure 1). The formation of free $\mathrm{P} t \mathrm{BMA}$ chains during the second step of the brush synthesis is likely the consequence of the high dilution that had to be employed for the telomerization of the PtBMA side chains.

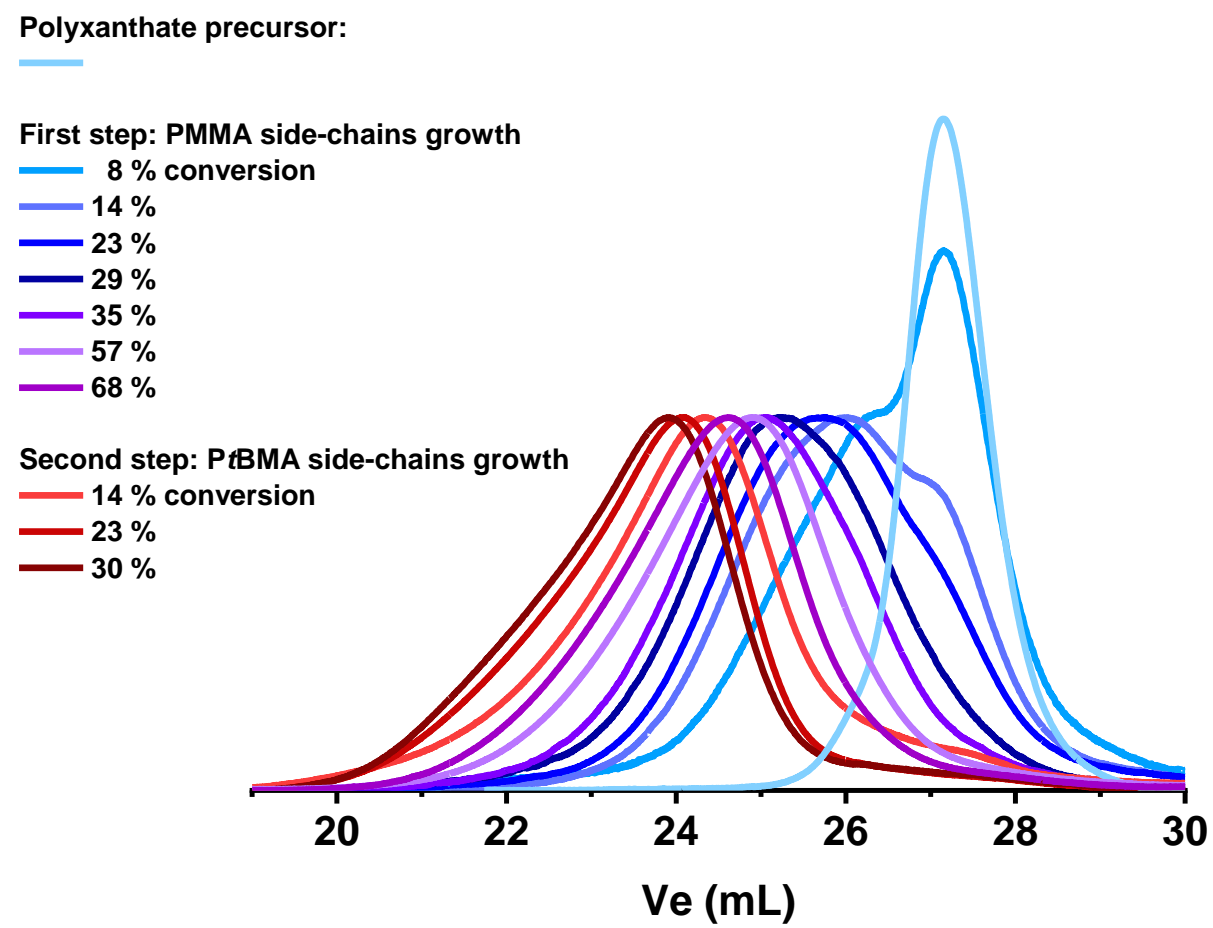

Figure 1. Evolution of SEC traces during the synthesis of the PMMA and P $t$ BMA side chains of the poly(PMMA-stat-PtBMA) heterografted brush used as a precursor of the amphiphilic poly(PMMA-stat-PMAA) brush copolymer P0. 
The poly(PMMA-stat-PtBMA) heterografted molecular brush was subsequently turned into an amphiphilic brush with PMAA hydrophilic side chains, by acidic hydrolysis of the tert-butyl ester functions of the $t$ BMA repeating units. Based on the integration of the characteristic peak of the tert-butyl group in ${ }^{1} \mathrm{H}$ NMR, more than $93 \%$ of the tert-butyl esters were hydrolyzed (Figure S3). FTIR spectroscopy was also used to confirm the hydrolysis. A broad band between 2500 to $3500 \mathrm{~cm}^{-1}$, characteristic of the stretching vibration of bonded $\mathrm{OH}$ functions of carboxylic acids, was clearly visible (Figure S3). In addition, the carbonyl stretching vibration at $1700 \mathrm{~cm}^{-1}$ slightly shifted to lower wavelength number after hydrolysis of the $t$-butyl ester moieties, which is consistent with the transformation of a fraction of the ester groups of the methacrylate repeating units into carboxylic acids. DSC characterization of the brush copolymers before and after hydrolysis of the tert-butyl ester moieties further confirmed the composition of the copolymer. While the poly(PMMA-stat-P $t$ BMA) brush showed only one $T_{\mathrm{g}}$ at $113^{\circ} \mathrm{C}$ (Figure $\mathbf{S 4}$ ), the poly(PMMA-stat-PMAA) heterografted brush $\mathbf{P 0}$ displayed two $T_{\mathrm{g}} \mathbf{S}$, (113 and $213{ }^{\circ} \mathrm{C}$ ), corresponding to $T_{\mathrm{g}}$ of PMMA and PMAA side chains, respectively. These results further confirm the efficient hydrolysis of $\mathrm{P} t \mathrm{BMA}$.

\subsubsection{Self-assembly of the poly(PMMA-stat-PMAA) heterografted brush P0}

The amphiphilic poly(PMMA-stat-PMAA) molecular brush P0 could not be directly dissolved in pure water and a co-solvent was used to induce self-assembly of the molecular brushes in water. The brushes were dissolved in DMF (1 wt\%) and water was added dropwise under vigorous stirring to reach a concentration of $1 \mathrm{~g} / \mathrm{L}$. A transparent solution was thus obtained (Figure S5), with a $\mathrm{pH}$ around 4.5. This co-solvent method was also applied to poly(MMA-stat- $t$ BMA) brush copolymer, i.e. before the hydrolysis step. Precipitation of the polymer was systematically observed immediately after the introduction of few drops of water (Figure S5). The solution of poly(MMA-stat-MAA) was then dialyzed to remove the DMF and aqueous solutions at various concentrations were prepared. 

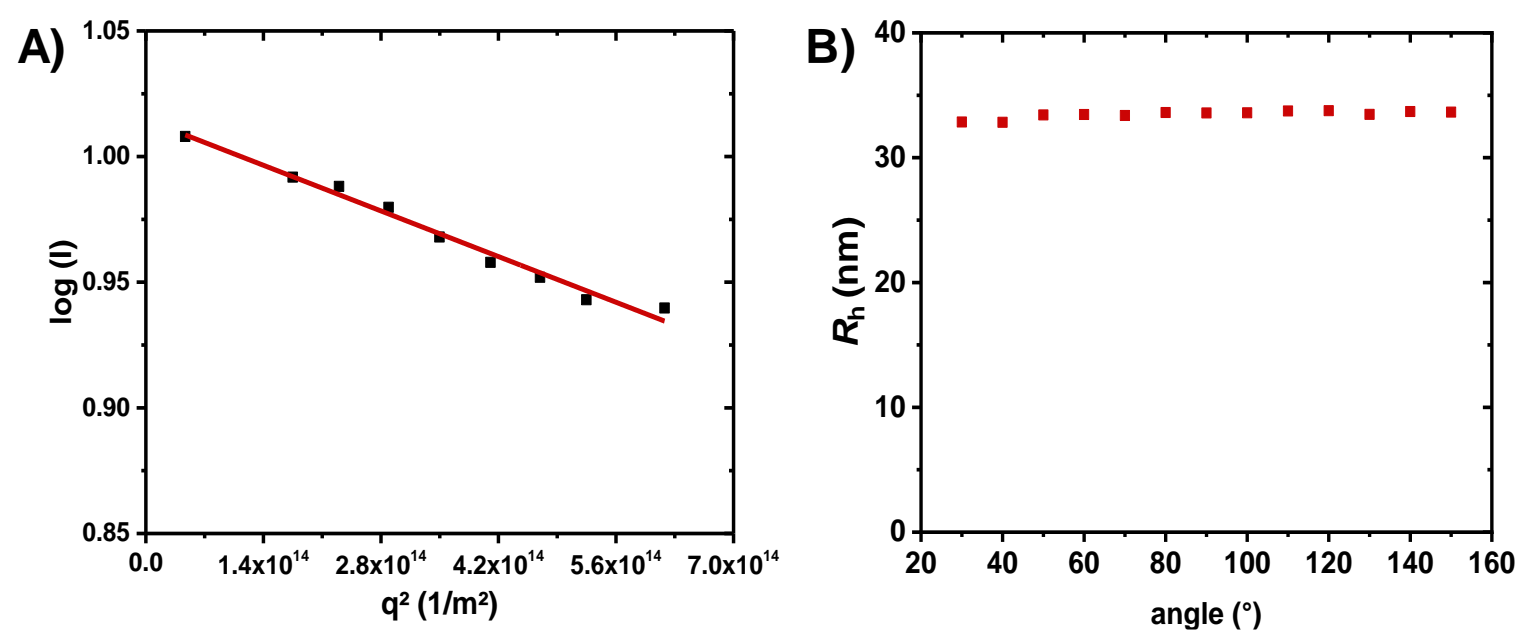

Figure 2. DLS measurements. A) Determination of the radius of gyration of the poly(PMMAstat-PMAA), P0, heterografted brush in DMF (1g/L) by plotting $\log (\mathrm{I})$ vs. $\left.\mathrm{q}^{2} ; \mathrm{B}\right)$ Plot of the hydrodynamic radius of the poly(PMMA-stat-PMAA), P0, heterografted brush in water $(1 \mathrm{~g} / \mathrm{L})$ as a function of the scattering angle.

DLS measurements were first performed in DMF, a good solvent of the poly(PMMA-statPMAA) heterografted brush, P0. A hydrodynamic radius, $R_{\mathrm{h}}$, of $15 \mathrm{~nm}$ was determined, while a radius of gyration, $R_{\mathrm{g}}$, of $18 \mathrm{~nm}$ was extracted from the plot of $\log (\mathrm{I})$ as a function of $\mathrm{q}^{2}$ (where I the intensity of the scattered light and q the wave vector) using Guinier approximation (Figure 2). The ratio $\rho$, defined as $R_{\mathrm{g}} / R_{\mathrm{h}}$, was equal to 1.2 , which is significantly smaller than the standard ratio $\rho$ of a polymer random coil in a good solvent (1.505), but agrees well with the branched structure of the molecular brush P0. DLS was then performed at different angles (from 30 to $150^{\circ}$ ) on aqueous solutions of $\mathbf{P 0}$. The measured $R_{\mathrm{h}}$ in water was about $33 \mathrm{~nm}$ and was independent of both the measurement angles (Figure 2) and the polymer concentration (Table S1). This observation is consistent with the formation of micelles resulting from the self-assembly of the amphiphilic poly(PMMA-stat-PMAA) brush copolymer to minimize the interactions between water and the hydrophobic PMMA side chains. For a polymer concentration of $0.1 \mathrm{mg} / \mathrm{L}$, no signal was recorded by DLS, which can be attributed to a loss of the self-assembly or to a concentration lower than the detection limit. For homogeneous sphere, 
$\rho$ is equal to 0.775 . This ratio was significantly lower in our case, with a value of $c a$. 0.58 (Table S1). This result is again consistent with the formation of micelles displaying a core-shell structure,[46] with an hydrophobic core made of PMMA side chains and a hydrophilic corona composed of hydrated PMAA side chains.

TEM was performed to further confirm the presence of micelles resulting from the selfassembly in water of the poly(PMMA-stat-PMAA) heterografted brush, P0 (Figure 3). The aggregates were quite spherical, with diameters ranging from 80 to $100 \mathrm{~nm}$. This value is higher than the one determined by DLS $\left(D_{\mathrm{h}}=66 \mathrm{~nm}\right)$, which probably reflects the flattening of micelles upon drying.

A fluorescence technique, using pyrene as a probe, was employed to determine $\mathrm{CMC}$ of the poly(PMMA-stat-PMAA) heterografted brush P0 in aqueous solution. Figure 3 shows the dependence of the fluorescence intensity ratio $\left(\mathrm{I}_{336.5} / \mathrm{I}_{333}\right)$ of pyrene as a function of the concentration of the poly(PMMA-stat-PMAA) brush. A CMC of $0.3 \mathrm{mg} / \mathrm{L}$ was determined with this technique. This value is in good agreement with the DLS measurements, which gave a CMC between 1 and $0.1 \mathrm{mg} / \mathrm{L}$.
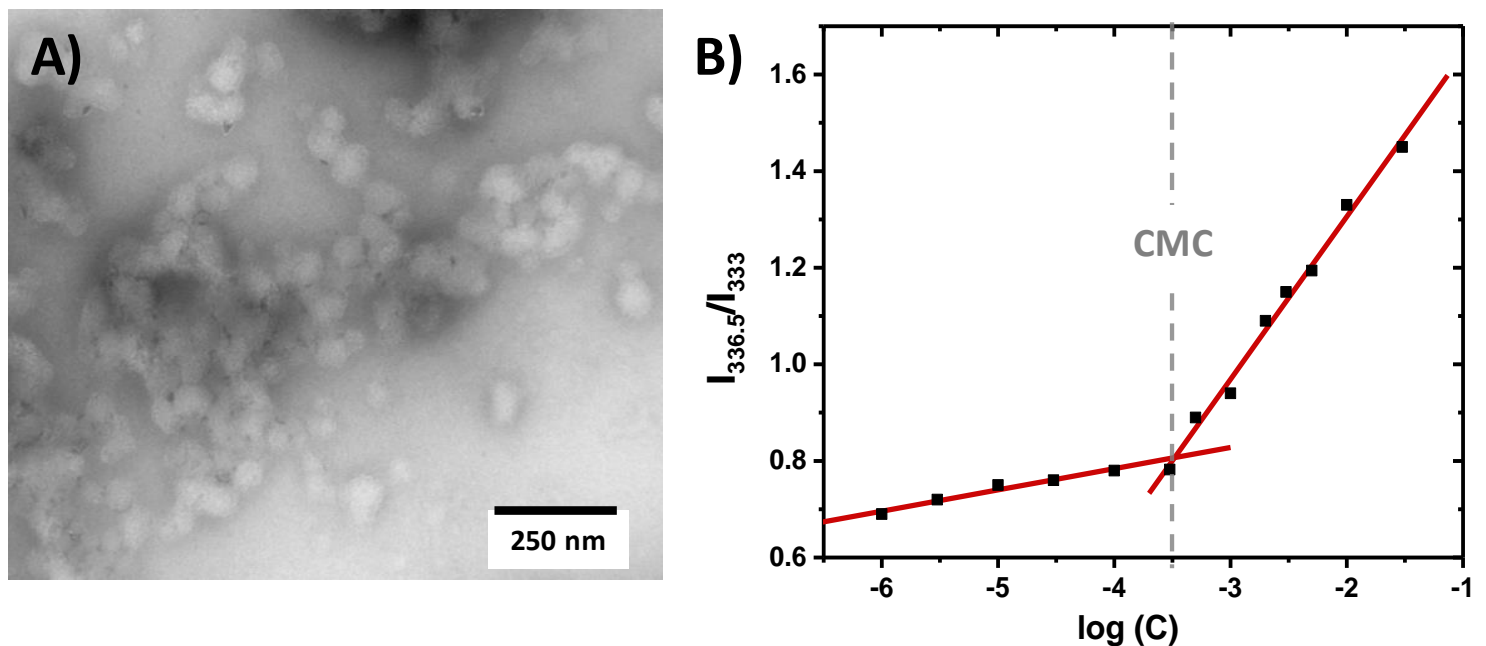

Figure 3. A) TEM image of an aqueous solution ( $1 \mathrm{~g} / \mathrm{L})$ of poly(PMMA-stat-PMAA) brush P0 dried at RT and stained with ruthenium tetraoxide. (b) Fluorescence intensity ratio $\mathrm{I}_{336.5} / \mathrm{I}_{333}\left(\lambda_{\mathrm{ex}}\right.$ $=373 \mathrm{~nm})$ of pyrene as a function of the concentration of poly(PMMA-stat-PMAA) brush P0 in aqueous solution. 


\subsection{Modulation of the structural parameters of the heterografted brushes and study of}

their self-assembly in water

The synthesis of molecular brushes by telomerization from a polythiol macrotransfer agent is not only a simple and robust approach, it constitutes a versatile methodology with regards to the structure and composition of the molecular brushes that can be prepared. Indeed, varying the amount of xanthates deprotected and the monomer to pendant thiols ratio during the successive telomerizations allow tuning the lengths of the side chains and the ratio of hydrophobic and hydrophilic grafts (Scheme 2).

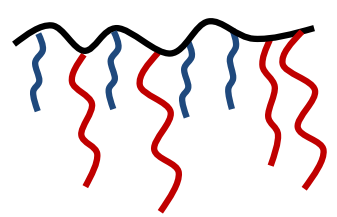

P1

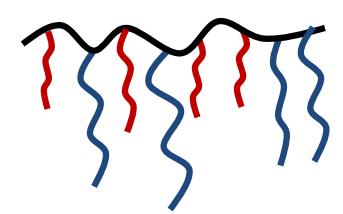

P2

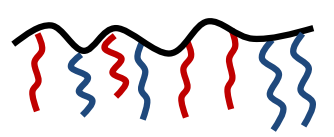

P3

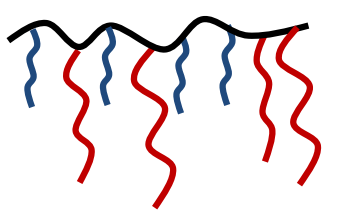

P1

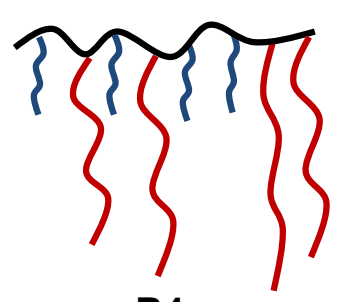

P4

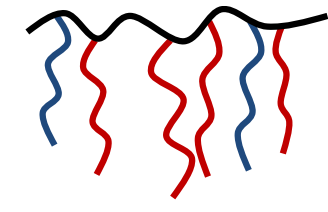

P5

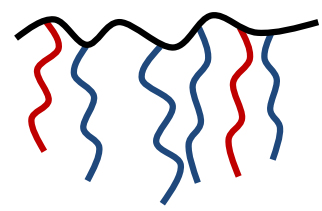

P6

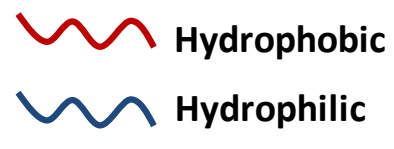

Scheme 2. Schematic representation of amphiphilic heterografted brushes prepared from a single polyxanthate precursor, displaying varying lengths of the side chains (P1 to P4) and ratios of hydrophobic and hydrophilic grafts (P5 and P6).

This versatility was exemplified by preparing a set of amphiphilic molecular brushes from a single polyxanthate precursor ( $M_{\mathrm{n}}$ of $41.7 \mathrm{~kg} / \mathrm{mol}$, DP of $c a .215$ and $Ð$ of 1.2 ) containing 70 mol\% of BenzMA and 30 mol\% of XEMA. Heterografted brushes with similar numbers of hydrophobic and hydrophilic side chains of varying lengths were prepared (Scheme 2, P1 to 
P4). In addition, heterografted brushes with different fractions of hydrophobic and hydrophilic grafts were also targeted (Scheme 2, P5 and P6). For this set of amphiphilic brushes, the hydrophobic PMMA segment was replaced by PBMA. Whereas the $T_{\mathrm{g}}$ of PMMA is superior to $100^{\circ} \mathrm{C}$, the $T_{\mathrm{g}}$ of PBMA is significantly lower, and around RT. Therefore, PBMA is more readily solubilized at RT. As a consequence, less solvent was required to conduct the polymerization of the second type of side chains, which allowed reaching higher monomer conversions. The ratio of hydrophobic (PBMA) to hydrophilic (PMAA) side chains, and their respective DP, are important parameters that directly impact the size of the micelles formed by the self-assembly of amphiphilic brushes. The heterografted brushes were synthesized following the procedure described for the synthesis of the poly(PMMA-stat-PMAA) brush P0, simply replacing MMA by BMA for the polymerization of the hydrophobic side chains and decreasing the amount of solvent used in the second telomerization. Under these conditions, the final monomer conversion at the end of the different telomerizations was systematically between 60 and $70 \%$. The different poly(PBMA-stat-PtBMA) heterografted brushes were isolated at the end of the synthesis by precipitation into methanol. Molecular brushes free of linear contaminant were systematically obtained this way (Figure S6 for a representative example). The heterografted brushes were then transformed into amphiphilic brushes by acidic hydrolysis of the tert-butyl ester functions of the PtBMA side chains. Micellar solutions in water were prepared for every amphiphilic molecular brushes using the co-solvent method. The aqueous solutions of polymer were then analyzed by DLS to determine the $R_{\mathrm{h}}$ of the micelles resulting from the self-assembly of the heterografted brushes (Table 1). 
Table 1. Molecular characteristics of the heterografted brushes and $R_{\mathrm{h}}$ of the micelles formed by self-assembly in water ${ }^{a}$

\begin{tabular}{lcccccccc} 
Brush & $\begin{array}{c}\text { Theoretical } \\
\text { number of PBMA } \\
\text { side chains per }_{\text {brush }^{b}}\end{array}$ & $\begin{array}{c}\text { Theoretical } \\
\text { number of PMAA } \\
\text { side chains per }_{\text {brush }^{b}}\end{array}$ & $\begin{array}{c}\text { DP of the } \\
\text { PBMA side } \\
\text { chains }^{c}\end{array}$ & $\begin{array}{c}\text { DP of the } \\
\text { PMAA side } \\
\text { chains }^{c}\end{array}$ & $\begin{array}{c}M_{\mathrm{n}, \mathrm{th}^{c}} \\
(\mathrm{~kg} / \mathrm{mol})\end{array}$ & $\begin{array}{c}M_{\mathrm{n}, \text { exp }}{ }^{d} \\
(\mathrm{~kg} / \mathrm{mol})\end{array}$ & $\mathrm{Ð}^{d}$ & $\begin{array}{c}R_{\mathrm{h}}{ }^{e} \\
(\mathrm{~nm})\end{array}$ \\
\hline $\mathbf{P 1}$ & 32 & 32 & 105 & 56 & 771 & 481 & 1.9 & 114 \\
$\mathbf{P 2}$ & 32 & 32 & 67 & 106 & 825 & 509 & 2.0 & 69 \\
$\mathbf{P 3}$ & 34 & 30 & 49 & 43 & 458 & 493 & 1.9 & 38 \\
$\mathbf{P 4}$ & 34 & 30 & 187 & 52 & 1170 & 935 & 1.8 & - \\
$\mathbf{P 5}$ & 49 & 15 & 81 & 85 & 784 & 532 & 1.8 & 129 \\
$\mathbf{P 6}$ & 15 & 49 & 71 & 70 & 677 & 720 & 1.7 & 38 \\
$\mathbf{P 7}$ & 32 & 32 & 66 & 105 & 769 & 740 & 1.9 & 31 \\
\hline
\end{tabular}

${ }^{a}$ prepared from a single polyxanthate precursor: $M_{\mathrm{n}}=41.7 \mathrm{~kg} / \mathrm{mol}, D=1.2 ; \mathrm{DP}=214,30 \mathrm{~mol} \%$ of XEMA, 70 mol $\%$ of BenzMA; ${ }^{b}$ determined by ${ }^{1} \mathrm{H}$ NMR, assuming quantitative initiation from the deprotected thiols during the telomerization step; ${ }^{c}$ based on monomer conversion (determined by ${ }^{1} \mathrm{H}$ NMR) and assuming a quantitative initiation from the deprotected thiols during the telomerization steps; ${ }^{d}$ determined by SEC triple detection in THF before $t$ BMA or $t$ BA hydrolysis; ${ }^{e}$ determined by DLS on aqueous solutions at $1 \mathrm{~g} / \mathrm{L} ;{ }^{f}$ PAA hydrophilic side chains instead of PMAA.

\subsubsection{Effect of side chains length on the self-assembly of heterografted brushes}

The influence of the length of the side chains was examined, keeping approximately 32 hydrophobic and 32 hydrophilic side chains per brush (P1 to P4, Scheme 2 and Table 1). Amphiphilic copolymers with similar molar masses, ca. $500 \mathrm{~kg} / \mathrm{mol}$, but different lengths of the hydrophilic and hydrophobic side chains were compared (P1 and P2, Scheme 2 and Table 1). The brush P1 presents long hydrophobic side chains and shorter hydrophilic grafts, while P2 has long hydrophilic grafts and shorter hydrophobic side chains. The micelles formed by the self-assembly of these two molecular brushes displayed significantly different $R_{\mathrm{h}}$, as determined by DLS of aqueous solutions containing $1 \mathrm{~g} / \mathrm{L}$ of the respective brush. Hydrodynamic radii of 114 and $69 \mathrm{~nm}$ were found for the micelles resulting from the selfassembly of $\mathbf{P 1}$ and $\mathbf{P 2}$, respectively. This significant difference of $R_{\mathrm{h}}$ is perfectly consistent with core-shell micelles with a hydrophobic core, for which the self-assembly is driven by 
hydrophobic interactions between the PBMA grafts. This was further confirmed by comparing heterografted brushes with similar lengths of the hydrophilic side chains (DP of $c a$. 50) but increasing lengths of the hydrophobic side chains (P3, P1 and P4, Scheme 2 and Table 1). To verify that the targeted brushes displayed the desired structures, the side chain initiation efficiency was determined for the heterografted molecular brush P3. To this aim, the amount of unreacted pendant thiols remaining at the end of each telomerization steps was quantified by UV-Vis measurements. It was found that the brush P3 carried 31 PBMA and 26 P $t$ BMA grafts in average, which corresponds to 91 and $87.3 \%$, respectively, of the number of PBMA and P $t$ BMA side chains that should have been formed with a quantitative initiation efficiency from the thiol groups.

Aqueous solutions containing $1 \mathrm{~g} / \mathrm{L}$ of the poly(PBMA-stat-PMAA) heterografted brushes P3, P1 and P4 were then prepared. The solutions containing the amphiphilic brushes P3 and P1 were fully transparent, while the micellar solution containing P4 was opaque and difficult to filter before DLS analysis. For polymer P4, the PMAA hydrophilic grafts are not long enough, and/or in sufficient quantity, to stabilize the hydrophobic core constituted of long hydrophobic PtBMA segments.[26] As a consequence, large instable aggregates were formed. DLS measurements confirmed that the increase of the hydrophobic segments induces an increase of the $R_{\mathrm{h}}$ of the core-shell micelles, going from 38 to $114 \mathrm{~nm}$ for micelles obtained from P3 and P1, respectively (Table 1). This behavior is consistent with observations reported in the literature for amphiphilic random[47-49] and block[50] copolymers, as well as amphiphilic brushes.[23]

\subsubsection{Effect of the hydrophilic-hydrophobic balance on the self-assembly of}

\section{heterografted brushes}

The synthesis of heterografted molecular brushes by telomerization also offers the possibility to vary the ratio of hydrophobic and hydrophilic side chains starting from a single polyxanthate 
precursor. P5 and P6 brush copolymers both contains PBMA and PMAA grafts with DPs of approximately 70-80 (Table 1). P5 contains 49 PBMA and 15 PMAA side chains in average, while P6 contains 15 PBMA and 49 PMAA grafts in average. Micellization of P6 in water using the co-solvent method gave fully transparent solutions, while P5 gave opaque solutions. Similarly to what was observed with $\mathbf{P 4}$, the low content of hydrophilic stabilizing repeating units (low number of hydrophilic grafts in the case of P5, and low DP of the hydrophilic side chains as compared to the hydrophobic side chains in the case of P4) leads to the exposure of the hydrophobic domains to water and micelle destabilization is observed.[26] Micelles resulting from the self-assembly of $\mathbf{P 6}$ displayed a rather low $R_{\mathrm{h}}$ of $38 \mathrm{~nm}$. On the other hand, a $R_{\mathrm{h}}$ of $129 \mathrm{~nm}$ was found for aggregates resulting from the self-assembly of $\mathbf{P 5}$, for which the hydrophobic content is too high to get stable micelles. Interestingly, the increase of the dimension of the micelles with the content of the hydrophobic grafts observed for the selfassembly of the amphiphilic brushes follows a similar trend to that reported by Terashima et $a l$. for well-defined amphiphilic random copolymers prepared by reversible deactivation radical polymerization.[47]

The surfactant properties of the heterografted brushes depend on the ratio between hydrophilic and hydrophobic repeating units present in the grafts and backbone.[37, 51] Indeed, the amphiphilic heterografted brushes self-assemble in aqueous solutions to form micelles, with the hydrophobic side chains hidden in the core to minimize interfacial free energy between the hydrophobic segments and water. Therefore, the CMC in water of such brushes should decrease with the increase of the hydrophobic character of the brush.[26, 52] The CMC of the brush P6, whose side chains contain approximately three times more hydrophilic MAA than hydrophobic BMA repeating units, and of the brush $\mathbf{P 3}$, which contains approximately as many hydrophobic and hydrophilic monomer units in its side chains, were compared to the CMC of the brush P0, whose grafts contain approximately three times more hydrophobic repeating units than 
hydrophilic MAA motifs. Decreasing CMC values of 2.1, 0.63 and $0.3 \mathrm{mg} / \mathrm{L}$ were found for water solutions of $\mathbf{P 6}, \mathbf{P 3}$ and $\mathbf{P 0}$, respectively, thereby confirming the correlation between the CMC and the hydrophilic-hydrophobic balance (Figure S7). It should be pointed out that the amphiphilic brush containing the higher hydrophobic character, P0, presents a low CMC as compared to heterografted brushes of similar dimensions recently reported in the literature,[23, $24,37]$ which is a highly desirable feature for many applications. [2, 53]

\subsubsection{Effect of the $\mathrm{pH}$ on the self-assembly of the poly(PMMA-stat-PMAA) heterografted brush P6}

Interestingly, the amphiphilic brush copolymers contain ionizable hydrophilic PMAA grafts, whose charge content is $\mathrm{pH}$-dependent. DLS measurements on aqueous solutions $(1 \mathrm{~g} / \mathrm{L})$ of the amphiphilic brush P6 (15 PBMA and 49 PMAA side chains, both with a DP of $c a$. 70) were performed at different pHs to determine the size of the micelles (Figure 4). An increase of the size of the micelles with $\mathrm{pH}$ was observed, with a $R_{\mathrm{h}}$ increasing from $25 \mathrm{~nm}$ at $\mathrm{pH} 2$, to $80 \mathrm{~nm}$ at high $\mathrm{pH} 10$. The increase of the $R_{\mathrm{h}}$ with the $\mathrm{pH}$ was not linear, with a much more pronounced variation of the $R_{\mathrm{h}}$ nearby the $\mathrm{pKa}$ of the carboxylic acid function. This behavior reflects the deprotonation of the MAA as $\mathrm{pH}$ increases, and the swelling of the hydrophilic corona. This phenomenon was reversible and shrinking of the micelles was observed with lowering of the $\mathrm{pH}$. 


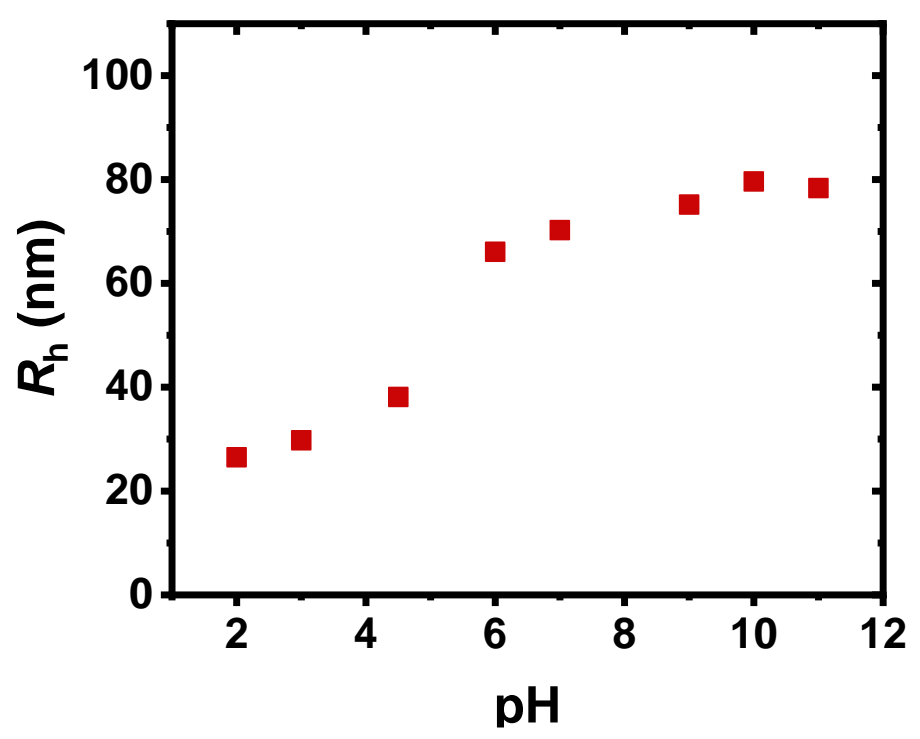

Figure 4. DLS measurements, as a function of $\mathrm{pH}$, of the hydrodynamic radius of micelles formed by the self-assembly of the poly(PBMA-stat-PMAA) brush P6 in aqueous solutions $(1 \mathrm{~g} / \mathrm{L})$

\subsubsection{Amphiphilic brushes with PAA and PNIPAM hydrophilic side chains}

To further exemplify the versatility of the developed approach, an heterografted brush with PBMA and poly(acrylic acid) side chains, P7, was also synthesized from the same polyxanthate precursor (Table 1). To this aim, half of the thiol moieties of the polyxanthate brush precursor were deprotected by aminolysis, followed by PBMA grafts growth, using a ratio $[\mathrm{BMA}] /[\mathrm{SH}] /[\mathrm{AIBN}]$ of $75 / 1 / 0.01$. The resulting brush was isolated by precipitation into methanol, and the synthesis of the poly(tert-butyl acrylate) (PtBA) grafts was achieved via a two-step process, i.e. with polymer isolation after thiol deprotection. This isolation step was necessary to avoid Michael addition of the thiols onto tert-butyl acrylate, which is catalyzed by the primary amine used to aminolyze the xanthate function. [40, 41, 43] The polymerization of $t$ BA was performed at $65^{\circ} \mathrm{C}$ in toluene, using a ratio $[t \mathrm{BA}] /[\mathrm{SH}] /[\mathrm{AIBN}]$ of $115 / 1 / 0.01$. The polymerization of $t \mathrm{BA}$ was conducted to high conversion, without detecting free linear chains nor intermolecular coupling of the brush copolymers by SEC (Figure 5). The characterization 
of the isolated heterografted brush copolymer by SEC triple detection gave a $M_{\mathrm{n}}$ of $740 \mathrm{~kg} / \mathrm{mol}$ and $Ð$ of 1.9 , in very good agreement the theoretical $M_{\mathrm{n}}$ of $770 \mathrm{~kg} / \mathrm{mol}$. The $\mathrm{P} t \mathrm{BA}$ side chains were then hydrolyzed, and the micelles formed through the self-assembly of the resulting amphiphilic brush copolymer P7 in aqueous solution were characterized by DLS. A $R_{\mathrm{h}}$ of 31 nm was found for these core-shell micelles.

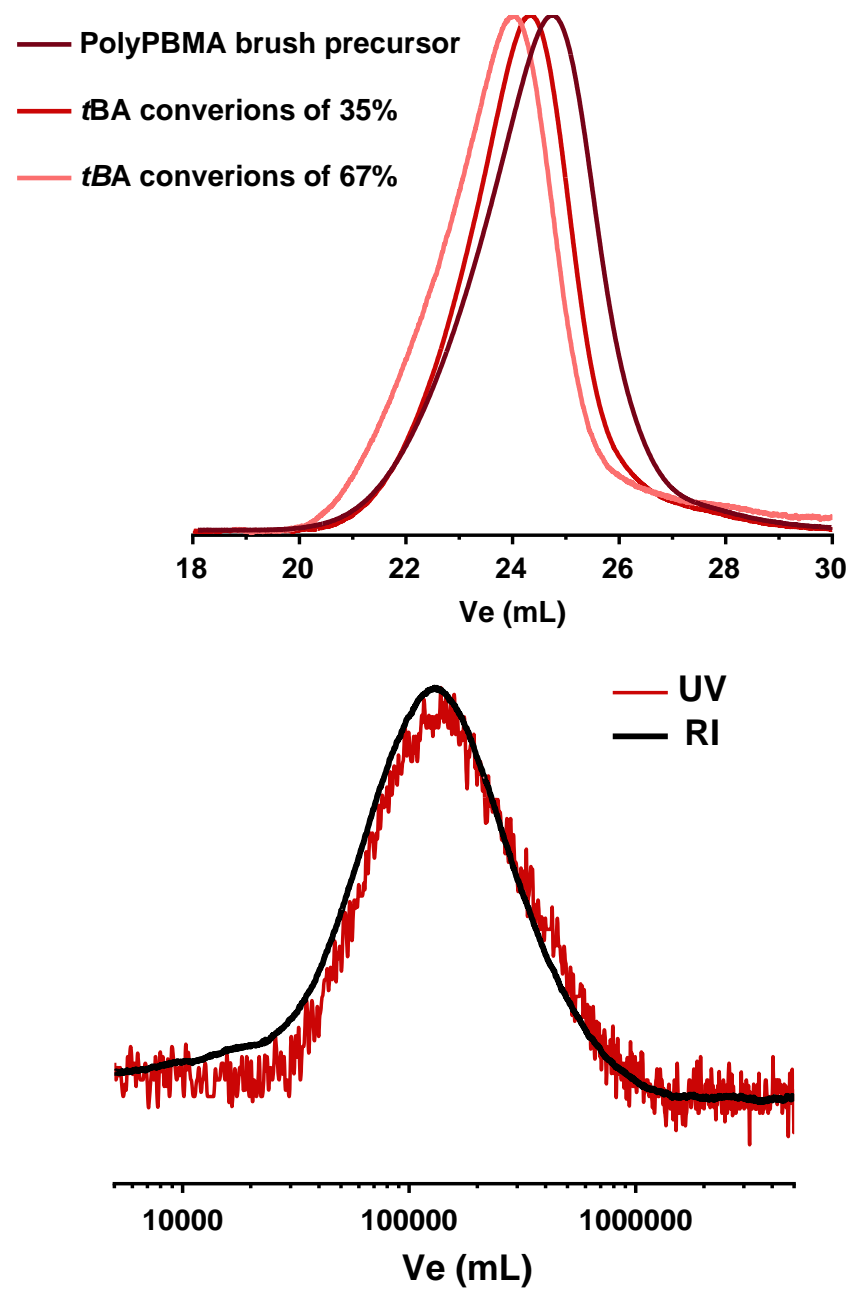

Figure 5. Top: Evolution of SEC traces during the telomerization of the $\mathrm{P} t \mathrm{BA}$ grafts of the poly(PBMA-stat-PtBA) heterografted brush used as a precursor of the amphiphilic poly(PBMA-stat-PAA) brush copolymer P7. Polymerization conducted in toluene at $65^{\circ} \mathrm{C}$, with a ratio $[t \mathrm{BA}]_{0} /[\mathrm{SH}]_{0} /[\mathrm{AIBN}]_{0}=115 / 1 / 0.01 ;$ Bottom: $\mathrm{SEC}$ traces obtained from refractometer and UV spectrometer detectors of the isolated poly(PBMA-stat-PNIPAM) brush copolymer P8. 
The synthesis of molecular brushes by telomerization from a polythiol macrotransfer agents is not limited to (meth)acrylates, but can also be applied to acrylamides.[40] Among this family of monomers, $\mathrm{N}$-isopropylacrylamide is of high interest, as it gives access to stimuli responsive polymers exhibiting a lower critical solution temperature (LCST) of ca. $33{ }^{\circ} \mathrm{C}$ in water.[3, 5456] Heterografted poly(BMA-stat-NIPAM) brushes were prepared from the same polyxanthate precursor that was used to synthesize the brush P0, i.e. $M_{\mathrm{n}}$ of $25 \mathrm{~kg} / \mathrm{mol}$, DP of $c a .130$ and $30 \mathrm{~mol} \%$ of XEMA. The synthesis of PNIPAM side chains was performed via a two-step process, i.e. with polymer isolation after thiol deprotection, similarly to the synthesis of the PtPBA grafts of $\mathbf{P 7}$. The polymerization of NIPAM was performed at $65{ }^{\circ} \mathrm{C}$ in DMF, using a ratio $[\mathrm{NIPAM}]_{0} /[\mathrm{SH}]_{0} /[\mathrm{AIBN}]_{0}$ of $60 / 1 / 0.01$. A monomer conversion of $60 \%$ was obtained under these conditions. The resulting brush copolymer $\mathbf{P 8}$ was isolated by successive precipitations into methanol. Characterization of P8 by SEC triple detection in THF gave a $M_{\mathrm{n}}$ of $293 \mathrm{~kg} / \mathrm{mol}$ and $Ð$ of 1.6 (Figure 5). A DP of 79 and 30 was found by ${ }^{1} \mathrm{H}$ NMR for the PBMA and PNIPAM side chains, respectively, assuming a quantitative initiation efficiency from the pendant thiols (Figure S8). These values are in very good agreement with the theoretical DP of the PBMA and PNIPAM grafts calculated from BMA and NIPAM conversions $\left(\mathrm{DP}_{\text {th }}=\left([\text { Monomer }]_{0} \times\right.\right.$ conv. $\left.) /[\mathrm{SH}]_{0}\right)$, which were 78 and 36 , respectively. This good match confirms that very few free polymer chains were formed under these conditions during the growth of the grafts by telomerization. DLS on an aqueous solution of the poly(BMA-stat-NIPAM) brush P8 at a concentration of $1 \mathrm{~g} / \mathrm{L}$ gave a $R_{\mathrm{h}}$ of $46 \mathrm{~nm}$ and a $R_{\mathrm{g}}$ of $27 \mathrm{~nm}$, corresponding to a $\rho$-ratio of 0.59 , in accordance with the formation of core-shell micelles.

\section{Conclusion}

The synthesis of amphiphilic heterografted molecular brushes by telomerization from polyxanthate precursors was successfully performed through successive steps of xanthate 
aminolysis and telomerization from the resulting thiol side groups. The applicability of this methodology to methacrylate, acrylate and acrylamide monomers was demonstrated through the synthesis of neutral and charged amphiphilic brushes. Molecular brushes with adjustable hydrophilic-hydrophobic balance and DP of their PBMA and PMAA side chains could be prepared from a single polyxanthate precursor. These brushes self-assembled in aqueous solution, as evidenced by DLS, to form core-shell micelles with $R_{\mathrm{h}}$ ranging from $30 \mathrm{~nm}$ to more than $100 \mathrm{~nm}$, depending on their molecular structure. In addition, the CMCs could be tuned by one order of magnitude by adjusting the hydrophilic-hydrophobic balance of the grafts, and a

$\mathrm{CMC}$ as low as $0.3 \mathrm{mg} / \mathrm{L}$ could be obtained. Therefore, despite their dispersity, which is inherent to the synthetic methodology developed, amphiphilic molecular brushes prepared by telomerization efficiently self-assemble to form stable micelles whose size and stability can be tuned, and are comparable to that of micelles obtained through the self-assembly of welldefined heterografted brushes prepared with much more sophisticated and demanding synthetic approaches. Consequently, telomerization from xanthate protected polythiol macrotransfer agents offers a straightforward and versatile methodology to prepare heterografted brushes, which should be of interest in areas of materials science where the surfactant properties and the ease of synthesis of the molecular brushes are both important parameters.

\section{ASSOCIATED CONTENT}

\section{Supporting Information.}

NMR, IR, DSC, SEC characterization of the heterografted brushes. Photographs, DLS and fluorescence characterization of the micellar solutions of amphiphilic heterografted brushes.

\section{AUTHOR INFORMATION}

\section{Corresponding Author}

*Email: renaud.nicolay@espci.psl.eu 


\section{ORCID}

Renaud Nicolaÿ: 0000-0003-1165-2592

\section{Notes}

The authors declare no competing financial interest.

\section{ACKNOWLEDGMENT}

The authors are grateful to ESPCI, CNRS and PSL University for financial support. The authors thank the members of the Chimie Moléculaire, Macromoléculaire, Matériaux laboratory for their valuable help.

\section{REFERENCES}

[1] S.S. Sheiko, B.S. Sumerlin, K. Matyjaszewski, Cylindrical molecular brushes: Synthesis, characterization, and properties, Prog. Polym. Sci. 33(7) (2008) 759-785.

[2] G. Xie, M.R. Martinez, M. Olszewski, S.S. Sheiko, K. Matyjaszewski, Molecular Bottlebrushes as Novel Materials, Biomacromolecules 20(1) (2019) 27-54.

[3] H.-i. Lee, J. Pietrasik, S.S. Sheiko, K. Matyjaszewski, Stimuli-responsive molecular brushes, Progress in Polymer Science 35(1-2) (2010) 24-44.

[4] J. Rzayev, Molecular Bottlebrushes: New Opportunities in Nanomaterials Fabrication, ACS Macro Lett. 1(9) (2012) 1146-1149.

[5] M. Mullner, A.H.E. Muller, Cylindrical polymer brushes - Anisotropic building blocks, unimolecular templates and particulate nanocarriers, Polymer 98 (2016) 389-401.

[6] M. Vatankhah-Varnosfaderani, W.F.M. Daniel, M.H. Everhart, A.A. Pandya, H. Liang, K. Matyjaszewski, A.V. Dobrynin, S.S. Sheiko, Mimicking biological stress-strain behaviour with synthetic elastomers, Nature 549 (2017) 497-501.

[7] T. Pakula, Y. Zhang, K. Matyjaszewski, H.-i. Lee, H. Boerner, S. Qin, G.C. Berry, Molecular brushes as super-soft elastomers, Polymer 47(20) (2006) 7198-7206. 
[8] W.F.M. Daniel, J. Burdynska, M. Vatankhah-Varnoosfaderani, K. Matyjaszewski, J. Paturej, M. Rubinstein, A.V. Dobrynin, S.S. Sheiko, Solvent-free, supersoft and superelastic bottlebrush melts and networks, Nat. Mater. 15(2) (2016) 183-189.

[9] A. Nese, N.V. Lebedeva, G. Sherwood, S. Averick, Y. Li, H. Gao, L. Peteanu, S.S. Sheiko, K. Matyjaszewski, pH-Responsive Fluorescent Molecular Bottlebrushes Prepared by Atom Transfer Radical Polymerization, Macromolecules 44(15) (2011) 5905-5910.

[10] H. Xu, F.C. Sun, D.G. Shirvanyants, M. Rubinstein, D. Shabratov, K.L. Beers, K. Matyjaszewski, S.S. Sheiko, Molecular pressure sensors, Adv. Mater. 19(19) (2007) 29302934.

[11] X. Banquy, J. Burdynska, D.W. Lee, K. Matyjaszewski, J. Israelachvili, Bioinspired Bottle-Brush Polymer Exhibits Low Friction and Amontons-like Behavior, J. Am. Chem. Soc. 136(17) (2014) 6199-6202.

[12] B. Xu, C. Feng, J. Hu, P. Shi, G. Gu, L. Wang, X. Huang, Spin-Casting Polymer Brush Films for Stimuli-Responsive and Anti-Fouling Surfaces, ACS Appl. Mater. Interfaces 8(10) (2016) 6685-6692.

[13] G. Sun, S. Cho, C. Clark, S.V. Verkhoturov, M.J. Eller, A. Li, A. Pavia-Jimenez, E.A. Schweikert, J.W. Thackeray, P. Trefonas, K.L. Wooley, Nanoscopic Cylindrical Dual Concentric and Lengthwise Block Brush Terpolymers as Covalent Preassembled HighResolution and High-Sensitivity Negative-Tone Photoresist Materials, J. Am. Chem. Soc. 135(11) (2013) 4203-4206.

[14] P.J.M. Stals, Y. Li, J. Burdynska, R. Nicolay, A. Nese, A.R.A. Palmans, E.W. Meijer, K. Matyjaszewski, S.S. Sheiko, How Far Can We Push Polymer Architectures?, J. Am. Chem. Soc. 135(31) (2013) 11421-11424. 
[15] Y. Xia, B.D. Olsen, J.A. Kornfield, R.H. Grubbs, Efficient Synthesis of Narrowly Dispersed Brush Copolymers and Study of Their Assemblies: The Importance of Side Chain Arrangement, J. Am. Chem. Soc. 131(51) (2009) 18525-18532.

[16] K. Kawamoto, M. Zhong, K.R. Gadelrab, L.-C. Cheng, C.A. Ross, A. Alexander-Katz, J.A. Johnson, Graft-through Synthesis and Assembly of Janus Bottlebrush Polymers from ABranch-B Diblock Macromonomers, J. Am. Chem. Soc. 138(36) (2016) 11501-11504.

[17] Q. Yan, J. Yuan, F. Zhang, X. Sui, X. Xie, Y. Yin, S. Wang, Y. Wei, Cellulose-Based Dual Graft Molecular Brushes as Potential Drug Nanocarriers: Stimulus-Responsive Micelles, SelfAssembled Phase Transition Behavior, and Tunable Crystalline Morphologies, Biomacromolecules 10(8) (2009) 2033-2042.

[18] D. Zehm, A. Laschewsky, M. Gradzielski, S. Prevost, H. Liang, J.P. Rabe, R. Schweins, J. Gummel, Amphiphilic Dual Brush Block Copolymers as "Giant Surfactants" and Their Aqueous Self-Assembly, Langmuir 26(5) (2010) 3145-3155.

[19] K. Huang, J. Rzayev, Well-Defined Organic Nanotubes from Multicomponent Bottlebrush Copolymers, J. Am. Chem. Soc. 131(19) (2009) 6880-6885.

[20] R. Fenyves, M. Schmutz, I.J. Horner, F.V. Bright, J. Rzayev, Aqueous Self-Assembly of Giant Bottlebrush Block Copolymer Surfactants as Shape-Tunable Building Blocks, J. Am. Chem. Soc. 136(21) (2014) 7762-7770.

[21] J.-Z. Du, L.-Y. Tang, W.-J. Song, Y. Shi, J. Wang, Evaluation of Polymeric Micelles from Brush Polymer with Poly(e-caprolactone)-b-Poly(ethylene glycol) Side Chains as Drug Carrier, Biomacromolecules 10(8) (2009) 2169-2174.

[22] Y. Li, J. Zou, B.P. Das, M. Tsianou, C. Cheng, Well-Defined Amphiphilic Double-Brush Copolymers and Their Performance as Emulsion Surfactants, Macromolecules 45(11) (2012) 4623-4629. 
[23] B. Xu, G. Gu, C. Feng, X. Jiang, J. Hu, G. Lu, S. Zhang, X. Huang, (PAA-g-PS)-coPPEGMEMA asymmetric polymer brushes: synthesis, self-assembly, and encapsulating capacity for both hydrophobic and hydrophilic agents, Polym. Chem. 7(3) (2016) 613-624.

[24] T. Palacios-Hernandez, H. Luo, E.A. Garcia, L.A. Pacheco, M. Herrera-Alonso, Nanoparticles from Amphiphilic Heterografted Macromolecular Brushes with Short Backbones, Macromolecules 51(8) (2018) 2831-2837.

[25] W. Zhang, Y. Li, L. Liu, Q. Sun, X. Shuai, W. Zhu, Y. Chen, Amphiphilic Toothbrushlike Copolymers Based on Poly(ethylene glycol) and Poly( $\varepsilon$-caprolactone) as Drug Carriers with Enhanced Properties, Biomacromolecules 11(5) (2010) 1331-1338.

[26] S.C. Owen, D.P.Y. Chan, M.S. Shoichet, Polymeric micelle stability, Nano Today 7(1) (2012) 53-65.

[27] M. Hans, H. Keul, A. Heise, M. Moeller, Chemoenzymatic Approach toward Heterografted Molecular Bottle Brushes, Macromolecules 40(25) (2007) 8872-8880.

[28] Y. Li, F.H. Schacher, J. Ling, Synthesis of Polypeptoid-PolycaprolactonePolytetrahydrofuran Heterograft Molecular Polymer Brushes via a Combination of Janus Polymerization and ROMP, Macromol. Rapid Commun. 40(7) (2019) 1800905.

[29] K. Ishizu, N. Sawada, J. Satoh, A. Sogabe, Architecture and surfactant behavior of amphiphilic prototype copolymer brushes, J. Mater. Sci. Lett. 22(17) (2003) 1219-1222.

[30] D. Neugebauer, Y. Zhang, T. Pakula, K. Matyjaszewski, PDMS-PEO Densely Grafted Copolymers, Macromolecules 38(21) (2005) 8687-8693.

[31] H. Zhu, G. Deng, Y. Chen, Amphiphilic polymer brushes with alternating PCL and PEO grafts through radical copolymerization of styrenic and maleimidic macromonomers, Polymer 49(2) (2008) 405-411.

[32] T. Terashima, T. Sugita, K. Fukae, M. Sawamoto, Synthesis and Single-Chain Folding of Amphiphilic Random Copolymers in Water, Macromolecules 47(2) (2014) 589-600. 
[33] C.M. Bates, A.B. Chang, N. Momcilovic, S.C. Jones, R.H. Grubbs, ABA Triblock Brush Polymers: Synthesis, Self-Assembly, Conductivity, and Rheological Properties, Macromolecules 48(14) (2015) 4967-4973.

[34] N. Cakir, M. Yavuzarslan, H. Durmaz, G. Hizal, U. Tunca, Heterograft brush copolymers via romp and triple click reaction strategies involving CuAAC, diels-alder, and nitroxide radical coupling reactions, J. Polym. Sci., Part A: Polym. Chem. 51(4) (2013) 899-907.

[35] O.A. Candan, D. Kopan, H. Durmaz, G. Hizal, U. Tunca, Quadruple click reactions for the synthesis of cysteine-functional heterograft brush copolymer, Eur. Polym. J. 49(7) (2013) 17961802.

[36] P. Zhao, Y. Yan, X. Feng, L. Liu, C. Wang, Y. Chen, Highly efficient synthesis of polymer brushes with PEO and PCL as side chains via click chemistry, Polymer 53(10) (2012) 1992 2000

[37] G. Xie, P. Krys, R.D. Tilton, K. Matyjaszewski, Heterografted Molecular Brushes as Stabilizers for Water-in-Oil Emulsions, Macromolecules 50(7) (2017) 2942-2950.

[38] B. Xu, C. Feng, X. Huang, A versatile platform for precise synthesis of asymmetric molecular brush in one shot, Nat. Commun. 8(1) (2017) 1-8.

[39] D. Neugebauer, Y. Zhang, T. Pakula, K. Matyjaszewski, Heterografted PEO-PnBA brush copolymers, Polymer 44(22) (2003) 6863-6871.

[40] C. Teulere, R. Nicolay, Synthesis of molecular brushes by telomerization, Polymer Chemistry 8(34) (2017) 5220-5227.

[41] R. Nicolay, Synthesis of Well-Defined Polythiol Copolymers by RAFT Polymerization, Macromolecules 45(2) (2012) 821-827.

[42] K.A. Davis, K. Matyjaszewski, Atom Transfer Radical Polymerization of tert-Butyl Acrylate and Preparation of Block Copolymers, Macromolecules 33(11) (2000) 4039-4047. 
[43] M. Le Neindre, R. Nicolay, Polythiol copolymers with precise architectures: a platform for functional materials, Polymer Chemistry 5(16) (2014) 4601-4611.

[44] M. Le Neindre, B. Magny, R. Nicolay, Evaluation of thiocarbonyl and thioester moieties as thiol protecting groups for controlled radical polymerization, Polymer Chemistry 4(22) (2013) 5577-5584.

[45] M. Le Neindre, R. Nicolaÿ, One-pot deprotection and functionalization of polythiol copolymers via six different thiol-X reactions, Polymer International 63(5) (2014) 887-893.

[46] B. Hirzinger, M. Helmstedt, J. Stejskal, Light scattering studies on core-shell systems: determination of size parameters of sterically stabilized poly(methylmethacrylate) dispersions, Polymer 41(8) (2000) 2883-2891.

[47] S. Imai, Y. Hirai, C. Nagao, M. Sawamoto, T. Terashima, Programmed Self-Assembly Systems of Amphiphilic Random Copolymers into Size-Controlled and Thermoresponsive Micelles in Water, Macromolecules 51(2) (2018) 398-409.

[48] Y. Kimura, T. Terashima, Morphology transition of amphiphilic homopolymer selfassemblies in water triggered by pendant design and chain length, Eur. Polym. J. 139 (2020) 110001.

[49] H. Yamamoto, Y. Morishima, Effect of hydrophobe content on intra- and interpolymer self-associations of hydrophobically modified poly(sodium 2-(acrylamido)-2methylpropanesulfonate) in water, Macromolecules 32(22) (1999) 7469-7475.

[50] D.V. Pergushov, E.V. Remizova, M. Gradzielski, P. Lindner, J. Feldthusen, A.B. Zezin, A.H.E. Müller, V.A. Kabanov, Micelles of polyisobutylene-block-poly(methacrylic acid) diblock copolymers and their water-soluble interpolyelectrolyte complexes formed with quaternized poly(4-vinylpyridine), Polymer 45(2) (2004) 367-378. 
[51] S. Fusco, A. Borzacchiello, P.A. Netti, Perspectives on: PEO-PPO-PEO triblock copolymers and their biomedical applications, J. Bioact. Compat. Polym. 21(2) (2006) 149164.

[52] G.H. Van Domeselaar, G.S. Kwon, L.C. Andrew, D.S. Wishart, Application of solid phase peptide synthesis to engineering PEO-peptide block copolymers for drug delivery, Colloids and Surfaces B: Biointerfaces 30(4) (2003) 323-334.

[53] M.L. Adams, A. Lavasanifar, G.S. Kwon, Amphiphilic block copolymers for drug delivery, Journal of Pharmaceutical Sciences 92(7) (2003) 1343-1355.

[54] C. Li, N. Gunari, K. Fischer, A. Janshoff, M. Schmidt, New Perspectives for the Design of Molecular Actuators: Thermally Induced Collapse of Single Macromolecules from Cylindrical Brushes to Spheres, Angew. Chem., Int. Ed. 43(9) (2004) 1101-1104.

[55] D. Roy, J.N. Cambre, B.S. Sumerlin, Future perspectives and recent advances in stimuliresponsive materials, Prog. Polym. Sci. 35(1-2) (2010) 278-301.

[56] H. Wei, S.-X. Cheng, X.-Z. Zhang, R.-X. Zhuo, Thermo-sensitive polymeric micelles based on poly(N-isopropylacrylamide) as drug carriers, Prog. Polym. Sci. 34(9) (2009) 893910. 